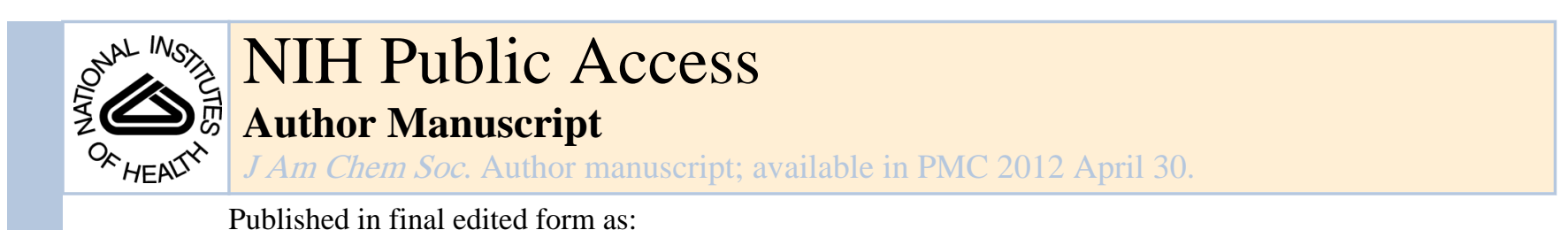

Published in final edited form as:

J Am Chem Soc. 2006 September 13; 128(36): 11764-11765. doi:10.1021/ja063735y.

\title{
Progressive-Convergent Elucidation of Stereochemistry in Complex Polyols. The Absolute Configuration of (-)-Sagittamide
}

\section{A}

\author{
Sarah C. Lievens ${ }^{\dagger}$ and Tadeusz F. Molinski ${ }^{\star}$ \\ Department of Chemistry and Biochemistry, University of California, San Diego, 9500 Gilman \\ Drive, La Jolla, CA 92093, and Department of Chemistry, UC Davis, One Shields Avenue, Davis, \\ CA 95616
}

\section{Abstract}

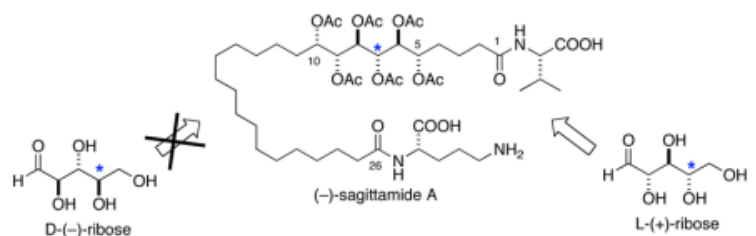

The absolute stereostructure of sagittamide A (1), a O-hexacetyl long-chain hexahydroxy-a, $\omega-$ dicarboxylic acid, was assigned using a progressive-convergent approach that integrates three powerful regimens for stereochemical analysis of acyclic natural products: J-based analysis, ${ }^{13} \mathrm{C}$ NMR universal database comparisons and exciton coupling circular dichroism.

The structure of (-)-sagittamide A (1) 1$)^{1}$-an unprecedented polyacetoxy, long-chain $a, \omega-$ dicarboxylic acid isolated from a tropical didemnid tunicate-was solved by application of conventional 2D NMR spectroscopic methods, however, only partial stereochemistry could assigned. Although configurations of the terminal amino acids (L-ornithine and L-valine) were determined readily by conventional methods, the contiguous 5,6,7,8,9,10-hexol hexaacetate in $\mathbf{1}$ represented a significantly more complex NMR problem, in part, because of isolated stereohexad $\mathrm{C} 5-\mathrm{C} 10$ flanked by $\mathrm{CH}_{2}$ groups ${ }^{2}$ and equivocal interpretations of $J$ coupling.

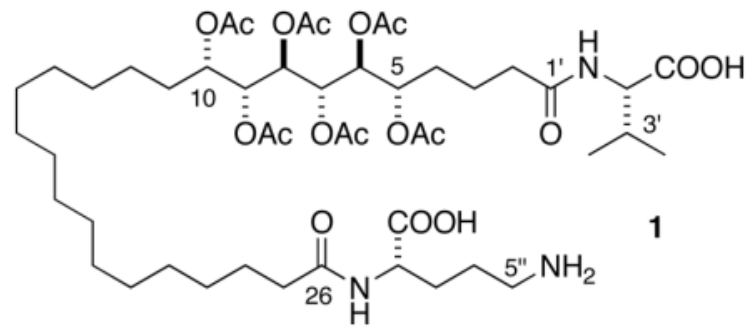

tmolinski@ucsd.edu.

†UC Davis

Supporting Information Available: Preparation of ribo- and xylo-model model compounds, and their stereochemical assignments, $\Delta \delta$ 's of xylo-models, ${ }^{1} \mathrm{H},{ }^{13} \mathrm{C}$ NMR and MS spectral data. This material is available free of charge via the Internet at http://pubs.acs.org. 
We now report the complete stereostructure of $\mathbf{1}$ using a progressive-convergent approach that integrates three powerful regimens for stereochemical analysis of natural products: use of Murata's $J$-based analysis $\left({ }^{3} J_{\mathrm{HH}}\right.$ and $\left.{ }^{2,3} J_{\mathrm{HC}}\right),{ }^{3}$ application of Kishi's Universal Database ${ }^{4}$ (pairwise-comparison of ${ }^{13} \mathrm{C}$ NMR chemical shifts with stereo-defined models) and highly sensitive exciton coupling circular dichroism (ECCD). ${ }^{5}$ The integrated approach rapidly converges upon a unique stereochemical assignment for $\mathbf{1}$ with internal validation.

A basis set of ${ }^{3} J_{\mathrm{HH}}$ and ${ }^{2,3} J_{\mathrm{CH}}$ values were obtained by $2 \mathrm{D}$ heteronuclear $2 \mathrm{D}$ NMR experiments of $\mathbf{1}$ (COSY and HSQMBC, respectively, see Supporting Information) and used to predict an all anti-relative configuration for $\mathrm{C} 6-\mathrm{C} 9$ for 1 . Consequently, the number of remaining possible diastereomers of $\mathbf{1}$ was reduced from $N=32$ to 4 . A synthetic route to six model compounds, representing permutations of the six stereocenters $\mathrm{C} 5-\mathrm{C} 10$ congruent with those proposed for $\mathbf{1}$, was conceived and executed starting with D-xylose (see Supporting Information). ${ }^{6} \mathrm{In}$ order to address an equivocal $\mathrm{C} 8{ }^{3} J_{\mathrm{CH}}$ value in $\mathbf{1}$, a parallel set of models 2-9 was also prepared from D-ribose as described below (Scheme 1).

Indium-promoted Barbier reaction of D-ribose with allyl bromide gave a 2:1 mixture of epimeric homoallylic alcohols ${ }^{7} \mathbf{1 0}$ and $\mathbf{1 1}$ after protection. Each acetonide was deprotected and hydrogenated $\left(\mathrm{Pd} / \mathrm{C}, \mathrm{CF}_{3} \mathrm{CH}_{2} \mathrm{OH}, 1 \mathrm{~atm} \mathrm{H}_{2}\right)^{8}$ followed by Swern oxidation to the corresponding $\mathrm{C} 9$ aldehydes and homologation using two stereocomplementary methods ( $Z$ selective Wittig olefination using phosphonium salt 14 and $E$-selective Julia-Kocienski olefination with tetrazole $\mathbf{1 5}^{9}$ ) to give $\mathbf{1 2}$ and $\mathbf{1 3}$.

Stereoselective $\mathrm{OsO}_{4}$ dihydroxylation ${ }^{10}$ of $\mathbf{1 2}$ gave diols $\mathbf{1 6}$ and 17. In this manner, $E$ - and $Z$-olefins were converted to diol diastereomers and purified by HPLC, prior to deprotection to the hexaols. Peracetylation of each hexaol furnished the eight C7-C9 ribo-model compounds 2-9 and six xylo-models (Supporting information). The correct relative configuration of 1 emerged from ${ }^{13} \mathrm{C}$ NMR comparisons with the model compounds (Figure $1)^{4}$

The ${ }^{1} \mathrm{H}$ and ${ }^{13} \mathrm{C}$ NMR spectra of each peracetate model were carefully assigned from COSY and HMBC spectra. Pairwise comparisons of the differences of the ${ }^{13} \mathrm{C}$ chemical shifts $(\Delta \delta)$ for $\mathrm{C} 4-\mathrm{C} 11$ in model compounds and $\mathbf{1}$ clearly showed an excellent match for the $\mathrm{C} 8$ epimer 6 obtained from D-ribose, but an mismatch for the corresponding $x y l o-C 8$ epimer (e.g. C8: $\Delta \delta=+0.05$ and $-3.93 \mathrm{ppm}$, respectively, see Supporting Information). A valuable object lesson is revealed here that promotes a progressive-convergent approach to stereochemistry. Although anomalous ${ }^{3} J_{\mathrm{CH}}$ 's in $\mathbf{1}$ predicted an erroneous xylo-configuration during $J$-based analysis, ${ }^{11}$ this was readily rectified in the progressive ${ }^{13} \mathrm{C} \Delta \delta$ analysis allowing reassignment of $\mathrm{C} 8$ configuration to that of $\mathbf{6}$.

The absolute stereochemistry of $\mathbf{1}$ was secured by transformation of the natural product, and hexaol diastereomers corresponding to $\mathbf{6}$ and 7, to the per-benzoate ester derivatives, 18, 19 and 20, respectively, ${ }^{12}$ and comparison of their corresponding CD spectra (Figure 2). Since the fingerprint Cotton effects observed in the CD spectra of 18 and 19 were equal in magnitude but opposite in sign, the absolute configuration of $\mathbf{1}$ corresponds to ent-19 and is related to L-ribose. ${ }^{12}$ Thus, the complete configuration of sagittamide A (1) is depicted as $(5 S, 6 S, 7 S, 8 R, 9 R, 10 S)$.

In summary, we have deployed an integrated approach to solve the configuration of sagittamide A (1). The power of this triple-combination of methodologies lies in judicious interpretation of homonuclear ${ }^{3} J$ and heteronuclear ${ }^{2,3} J$ to provide partial stereochemical information which is then used to inform correct choices for synthesis of model compounds to be used in the next stage: ${ }^{13} \mathrm{C}$ NMR comparative analysis. 
A significant advantage is gained by a requirement for only a limited sub-set of stereomodel compounds without the necessity for synthesis of all 64 possible permutations. The progressive-convergent approach succeeds where other singular methods based on NMR may become irreducibly complex ${ }^{13}$ or rendered equivocal by second-order effects that militate against reliable stereochemical assignments.

\section{Supplementary Material}

Refer to Web version on PubMed Central for supplementary material.

\section{Acknowledgments}

We thank J. DeRopp (UC Davis) for assistance with NMR measurements and R. New (UC Riverside) and Y.X. Su (UCSD) for MS data. This work was supported by the NIH (CA85602).

\section{References}

1. Lievens SC, Molinski TF. Org Lett. 2005; 7(11):2281-2284. [PubMed: 15901189]

2. All attempts to convert $\mathbf{1}$ to a $\mathrm{C} 1-\mathrm{O} 5 \delta$-lactone (potentially useful for stereochemical assignment) using acid catalysis were unsuccessful

3. Murata M, Nakamura H, Tachibana K. J Org Chem. 1999; 64:866-876. [PubMed: 11674159]

4. (a) Kobayashi Y, Hayashi N, Kishi Y. Org Lett. 2002; 4:411-414. [PubMed: 11820892] (b) Kobayashi Y, Tan CH, Kishi Y. J Am Chem Soc. 2001; 123:2076-2078. [PubMed: 11456839] (c) Kobayashi Y, Lee J, Tezuka K, Kishi Y. Org Lett. 1999; 1:2177-2180. [PubMed: 10836072]

5. (a) Vazquez JT, Wiesler WT, Nakanishi K. J Am Chem Soc. 1987; 109:5586-5592.(b) Zhou P, Berova N, Nakanishi K, Knani M, Rohmer M. J Am Chem Soc. 1991; 113:4040-4042.(c) Harada, N.; Nakanishi, K. Circular Dichroic Spectroscopy: Exciton Coupling in Organic Stereochemistry. University Science Books; Mill Valley: 1983.

6. The carbons numbered $\mathrm{C} 7, \mathrm{C} 8$ and $\mathrm{C} 9$ in $\mathbf{1}$ map to $\mathrm{C} 4, \mathrm{C} 3$ and $\mathrm{C} 2$ of ribose or xylose, respectively. Thus, the stereochemical descriptors ' $\mathrm{xylo}^{-}$' and 'ribo-' in the context of this work refer to C7-C9 of 1.

7. The configuration of the major isomer was assigned by analogy with the well-known 1,2-synstereopreference for $\mathrm{In}^{\circ}$-promoted allylation of aldohexoses [ Kim E, Gordon DM, Schmid W, Whitesides GM. J Chem Org. 1993; 58:5500-5507.Kobayashi S, Nagayama S. J Org Chem. 1996; 61:2256-2257.] and subsequent conversion to the acetonides $\mathbf{1 0}$ and $\mathbf{1 1 .}$

8. Deprotection of $\mathbf{1 0}$ and $\mathbf{1 1}$ to the corresponding primary alcohols was rapidly effected when $\mathrm{CF}_{3} \mathrm{CH}_{2} \mathrm{OH}$ was used as solvent for hydrogenolysis. No reaction was observed in ethanol, even after several days at 3 atm $\mathrm{H}_{2}$.

9. Blakemore PR, Cole WJ, Kocienski PJ, Morley A. Synlett. 1998; (1):26-28.Both 14 and 15 were prepared from $\delta$-valerolactone in three and four steps, respectively (see Supporting Information).

10. Diastereomeric assignments of 5,6-diols were based on the expectation of anti-selectivity of $\mathrm{OsO}_{4}$ addition to allylic alcohols and confirmed by the outcomes from double-diastereoselection using the Sharpless asymmetric dihydroxylation (Kolb HC, VanNieuwenhze MS, Sharpless KB. Chem Rev. 1994; 94:2483-547.) and observed pseudo- $\mathrm{C}_{2}$ symmetry in the ${ }^{1} \mathrm{H}$ and ${ }^{13} \mathrm{C}$ NMR spectra of 2 and $\mathbf{8}$. See Supporting Information.

11. This observation suggests caution in using $J$-based methodology and over-reliance on the underlying assumption of all-staggered conformations and the accuracy of $J \mathrm{~s}$ measured in strongly coupled contiguous polyols that may not be amenable to first-order spin analysis.

12. The lactam-mono methyl ester that formed spontaneously upon treatment of $\mathbf{1}\left(\mathrm{CH}_{2} \mathrm{~N}_{2}, \mathrm{MeOH}-\right.$ ether, ref. 1) and the hexaols corresponding to 6 and 7 were each converted (excess $\mathrm{BzCl}$, pyridine, $40{ }^{\circ} \mathrm{C}$ ) to hexabenzoates $\mathbf{1 7}, \mathbf{1 8}$, and $\mathbf{1 9}$, respectively, after HPLC purification. Benzoylation at higher temperatures $\left(60-90^{\circ} \mathrm{C}\right)$ lead to significant formation of tetrabenzoyloxy-tetrahydrofuran.

13. The similarity of CD spectra of diastereomeric $\mathbf{1 9}$ and $\mathbf{2 0}$ reflect the dominance of the C7-C10 configuration on the Cotton effects. 
14. Rychnovsky SD, Rogers B, Yang G. J Org Chem. 1993; 58:3511-3515. 
<smiles>CCCC(OC(C)=O)[C@@H](OC(C)=O)[C@H](OC(C)=O)[C@H](OC(C)=O)[C@@H](OC(C)=O)C(OC(C)=O)OC(C)=O</smiles><smiles>CCCC(OC(C)=O)C(OC(C)=O)C(OC(C)=O)C(OC(C)=O)C(OC(C)=O)C(C)OC(C)=O</smiles><smiles>CCCC(OC(C)=O)C(OC(C)=O)[C@H](OC(C)=O)C(OC(C)=O)C(OC(C)=O)C(CCCC(=O)OC)OC(C)=O</smiles><smiles>CCCC(OC(C)=O)C(OC(C)=O)[C@@H](OC(C)=O)C(OC(C)=O)C(OC(C)=O)C(C)O[Na]</smiles><smiles>CCC[C@H](OC(C)=O)C(OC(C)=O)[C@H](OC(C)=O)C(OC(C)=O)[C@H](OC(C)=O)C(OC(C)=O)OC(C)=O</smiles><smiles></smiles><smiles>CCC[C@H](OC(C)=O)[C@H](OC(C)=O)[C@H](OC(C)=O)C(OC(C)=O)C(OC(C)=O)C(CCCC(=O)OC)OC(C)=O</smiles>

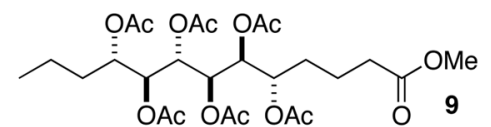

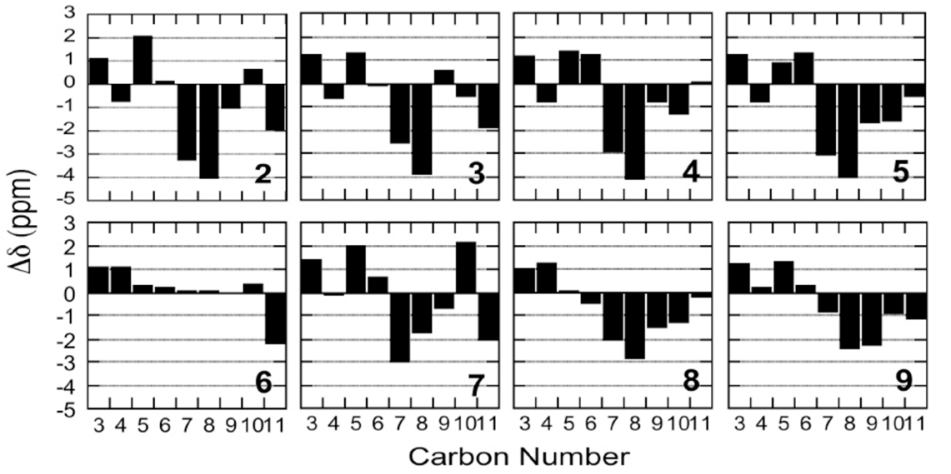

Figure 1.

${ }^{13} \mathrm{C}$ NMR $\left(125 \mathrm{MHz}, \mathrm{d}_{6}\right.$-DMSO, T=298 K) $\Delta \delta$ values $\left(\delta_{\mathrm{C}} \mathbf{1}-\delta_{\mathrm{C}}\right.$ model $)$ of ribo-model compounds 2-9 


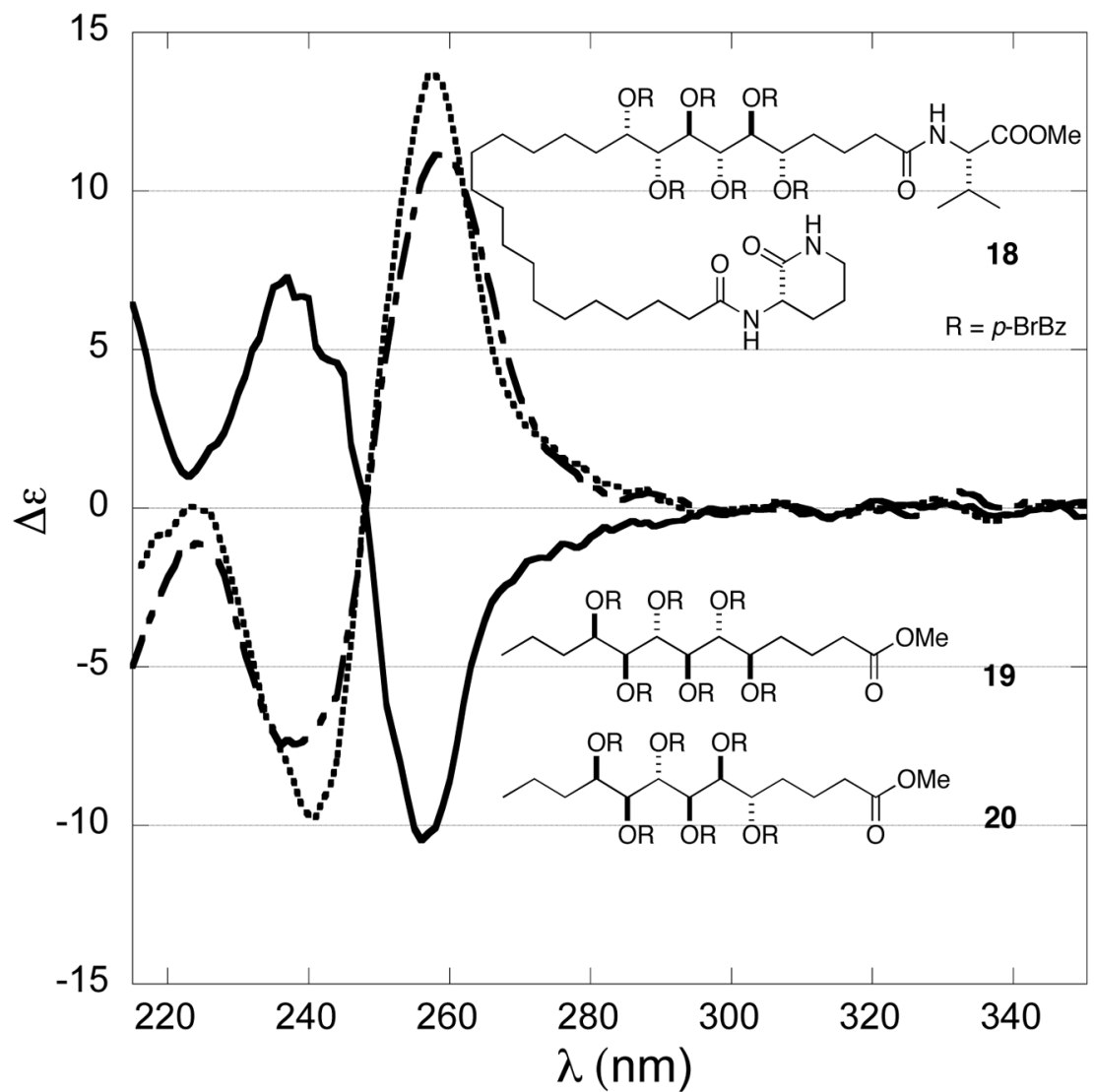

Figure 2.

CD spectra of sagittamide A derivative 18 (-), together with models 19 (...) and 20 (-- -), $\left(\mathrm{CH}_{3} \mathrm{CN}, \mathrm{c}=10 \mu \mathrm{M}\right)$. 


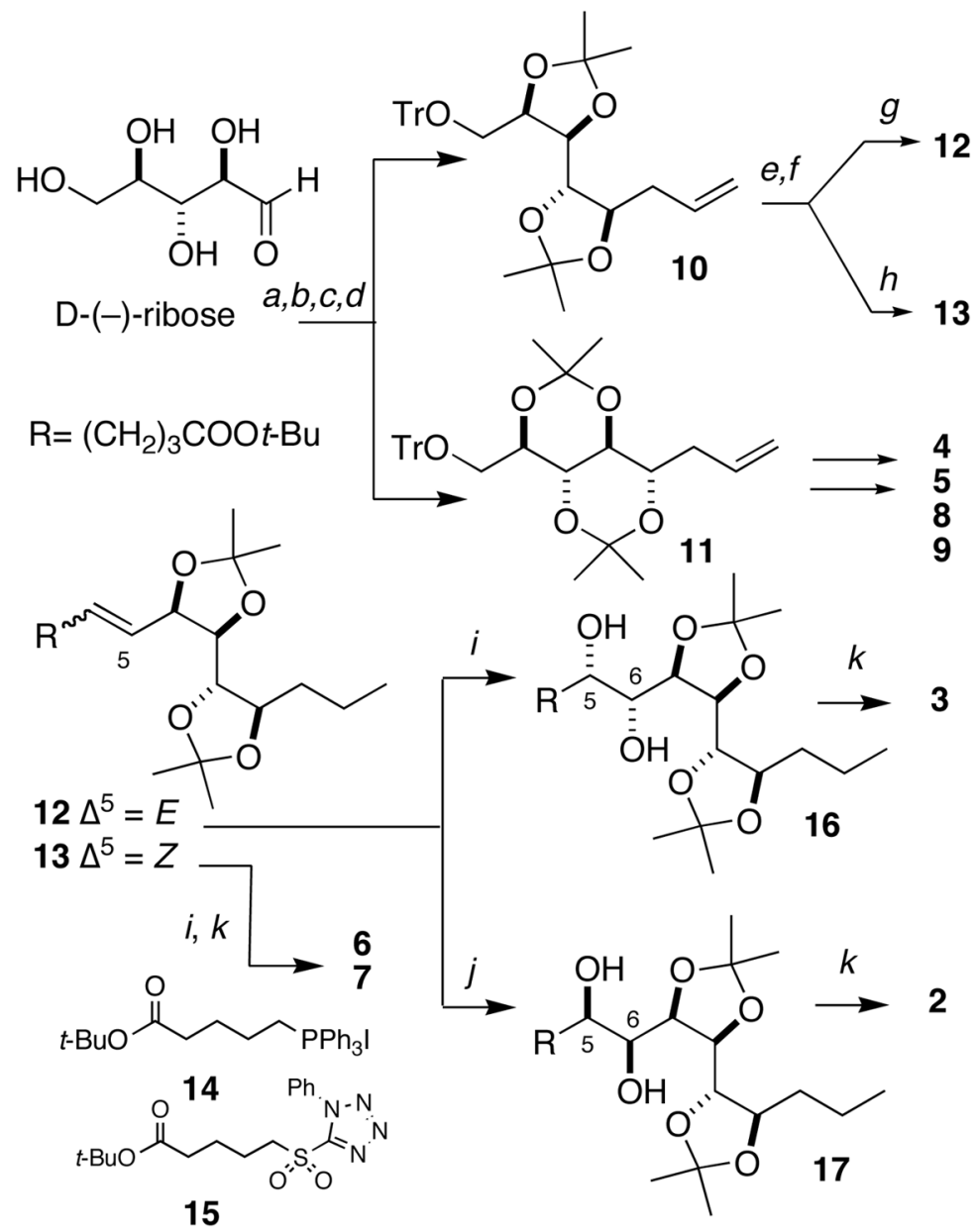

Scheme 1.

a) $\mathrm{In}^{\circ}$, allyl bromide, $\mathrm{H}_{2} \mathrm{O}$; b) $\mathrm{TrCl}$, pyridine, reflux 53\% (2 steps); c) CSA, acetone, $\mathrm{CH}_{3} \mathrm{C}\left(\mathrm{OCH}_{3}\right)_{2} \mathrm{CH}_{3}$ 58\%, 10:11 dr 2:1); d) $\mathrm{SiO}_{2}$-HPLC 1:19:EtOAc hexanes; e) $\mathrm{H}_{2}, 1$ atm, $\mathrm{Pd} / \mathrm{C}, \mathrm{CF}_{3} \mathrm{CH}_{2} \mathrm{OH}, 35-69 \%$; f) i. $(\mathrm{COCl})_{2}$, DMSO, $\mathrm{CH}_{2} \mathrm{Cl}_{2},-78{ }^{\circ} \mathrm{C}$ ii. $\mathrm{Et}_{3} \mathrm{~N}$; g) i. 15, DME, NaHMDS, $-78{ }^{\circ} \mathrm{C}$, ii. aldehyde, $25 \%$, dr 3:1 (2 steps); h) i. 14, THF, NaHMDS, $-78{ }^{\circ} \mathrm{C}$, ii. aldehyde, dr>19:1,16\% 2 steps; i) $\mathrm{OsO}_{4}$, $\mathrm{NMO}$, acetone, $\mathrm{H}_{2} \mathrm{O}$; dr 1.7:1, 93\%; j) $\mathrm{K}_{3} \mathrm{Fe}(\mathrm{CN})_{6}$, $\mathrm{K}_{2} \mathrm{OsO}_{4}, \mathrm{~K}_{2} \mathrm{CO}_{3}$ (DHQ) ${ }_{2} \mathrm{PHAL}$, t-BuOH, $\mathrm{H}_{2} \mathrm{O}, \mathrm{CH}_{3} \mathrm{SO}_{2} \mathrm{NH}_{2}$, dr 3.8:1, 86\%; k) $2 \%$ TMS$\mathrm{Cl}, \mathrm{MeOH}$, ii. $\mathrm{CH}_{2} \mathrm{~N}_{2}$, ether/ $\mathrm{MeOH}$, iii. $\mathrm{Ac}_{2} \mathrm{O}$, pyridine $6 \mathrm{~h}: 22 \% 3$ (3 steps), $48 \%$; 2 (3 steps), 44\%, 6 (4 steps), 26\%, 7 (4 steps). 